\title{
The effect of the water on the curcumin tautomerism: A quantitative approach
}

http://www.sciencedirect.com/science/article/pii/S1386142514008889 